Archived version from NCDOCKS Institutional Repository http://libres.uncg.edu/ir/asu/

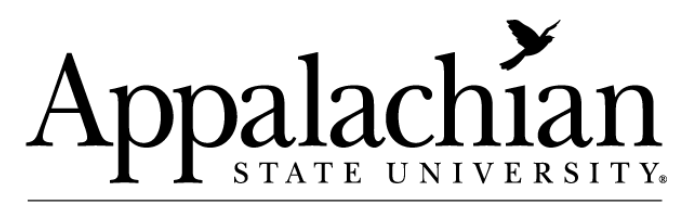

B O O N E, NORT H C A R O L I A

\title{
Patterns Of Dispersal In Sumatran Siamangs (Symphalangus syndactylus): Preliminary mtDNA Evidence Suggests More Frequent Male Than Female Dispersal To Adjacent Groups
}

\author{
By: Susan Lappan
}

\begin{abstract}
Gibbons of both sexes have been observed emigrating from their natal groups, but the consequences of dispersal in gibbons are poorly understood, and it is unclear whether these are the same for both sexes. I sequenced a 350 - bp fragment of mitochondrial DNA from 18 adults in seven siamang (Symphalangus syndactylus) groups at the Way Canguk Research Station in southern Sumatra to assess patterns of matrilineal relatedness among and within siamang groups, and to assess their fit with different patterns of sex - specific dispersal. A total of 11 haplotypes were identified in the seven study groups; $50 \%$ of adult males in five contiguous groups shared a haplotype with a member of an immediately adjacent group, whereas only $16.7 \%$ of females shared a haplotype with a neighbor. The apparent difference persisted if only same - sex individuals were considered $(37.5 \%$ of males vs. $0 \%$ of females). Four of the seven study groups contained two adult males and a single adult female. In three multimale groups, the three adults all had different haplotypes, suggesting that neither male was the retained adult offspring of the female, whereas in the fourth group, the haplotype of one male was identical with that of the adult female. The high diversity of haplotypes and the absence of clustering among female haplotypes in the study neighborhood suggest that female dispersal to territories adjacent to the natal group may be relatively rare. The presence of some clustering of male haplotypes suggests that shorter dispersal distances may be more common in males.
\end{abstract}

Lappan, S. (2007), Patterns of dispersal in Sumatran siamangs (Symphalangus syndactylus): preliminary mtDNA evidence suggests more frequent male than female dispersal to adjacent groups. Am. J. Primatol., 69: 692-698. doi:10.1002/ajp.20382. Publisher version of record available at: https://onlinelibrary.wiley.com/doi/10.1002/ ajp. 20382 


\title{
RESEARCH ARTICLE
}

\section{Patterns of Dispersal in Sumatran Siamangs (Symphalangus syndactylus): Preliminary mtDNA Evidence Suggests More Frequent Male Than Female Dispersal to Adjacent Groups}

\author{
SUSAN LAPPAN* \\ Department of Anthropology, San Diego State University, San Diego, California
}

Gibbons of both sexes have been observed emigrating from their natal groups, but the consequences of dispersal in gibbons are poorly understood, and it is unclear whether these are the same for both sexes. I sequenced a 350-bp fragment of mitochondrial DNA from 18 adults in seven siamang (Symphalangus syndactylus) groups at the Way Canguk Research Station in southern Sumatra to assess patterns of matrilineal relatedness among and within siamang groups, and to assess their fit with different patterns of sex-specific dispersal. A total of 11 haplotypes were identified in the seven study groups; $50 \%$ of adult males in five contiguous groups shared a haplotype with a member of an immediately adjacent group, whereas only $16.7 \%$ of females shared a haplotype with a neighbor. The apparent difference persisted if only same-sex individuals were considered (37.5\% of males vs. $0 \%$ of females). Four of the seven study groups contained two adult males and a single adult female. In three multimale groups, the three adults all had different haplotypes, suggesting that neither male was the retained adult offspring of the female, whereas in the fourth group, the haplotype of one male was identical with that of the adult female. The high diversity of haplotypes and the absence of clustering among female haplotypes in the study neighborhood suggest that female dispersal to territories adjacent to the natal group may be relatively rare. The presence of some clustering of male haplotypes suggests that shorter dispersal distances may be more common in males. Am. J. Primatol. 69:692-698, 2007. (c) 2006 Wiley-Liss, Inc.

Contract grant sponsor: Leakey Foundation; Contract grant sponsor: Sigma Xi; Contract grant sponsor: Fulbright Student Program; Contract grant sponsor: New York University; Contract grant sponsor: New York Consortium for Evolutionary Primatology.

*Correspondence to: Susan Lappan, Laboratory of Behavior and Ecology (B-365), Department of Life Sciences, Ewha University, Seodaemur-gu, Daehyun-dang 11-1, Seoul 120-750, Republic of Korea. E-mail: lappan@nyu.edu

Received 12 December 2005; revised 27 July 2006; revision accepted 14 August 2006

DOI 10.1002/ajp.20382

Published online 14 December 2006 in Wiley InterScience (www.interscience.wiley.com). 


\section{INTRODUCTION}

Gibbons (family Hylobatidae) are found primarily in groups containing a single adult of each sex, which suggests that maturing gibbons of both sexes typically emigrate from their natal groups. However, the consequences of natal emigration (e.g., dispersal distance, probability of mortality during emigration, probability of acquisition of a mate and territory) in gibbons are not well understood, and it is unclear whether these are the same for both sexes. Several previous studies report observations of relatively short dispersal distances for both male and female gibbons [e.g., Chivers \& Raemaekers, 1980; Raemaekers et al., 1984; Srikosamatara, 1984; Brockelman et al., 1998]. However, small group sizes and slow life histories have sharply limited the ability of researchers to document dispersal for gibbons, and the limited geographic scale of most gibbon studies has meant that the fates of many dispersers is unknown [Leighton, 1987], which produces a bias toward observation of short dispersal distances [Koenig et al., 1996].

Mitochondrial genetic data have been employed to evaluate patterns of dispersal and relatedness for several primate populations [e.g., Gerloff et al., 1999; Faulkes et al., 2003; Kappeler et al., 2002]. Short dispersal distances by members of either sex may lead to geographic clustering of mtDNA haplotypes. Clustering of female haplotypes has been reported for several primate species with male-biased dispersal patterns [e.g., Kappeler et al., 2002; Wimmer et al., 2002; Faulkes et al., 2003], and clustering of male haplotypes and matching young male-older female haplotypes have been reported in species with female-biased dispersal patterns [Gerloff et al., 1999].

As a preliminary step toward understanding siamang dispersal patterns, I sequenced a segment of mitochondrial DNA to explore patterns of maternal relatedness within and between six neighboring siamang groups at the Way Canguk Research Station in southern Sumatra, and to assess their fit with different sex-specific dispersal patterns.

\section{METHODS}

\section{Study Area}

The Way Canguk Research Station is located in the Bukit Barisan Selatan National Park on the island of Sumatra, Indonesia. The research area, which is run collaboratively by the Wildlife Conservation Society-Indonesia Program (WCS-IP) and the Indonesian Ministry of Forestry's Department for Protection and Conservation of Nature (PHKA), encompasses 900 ha of lowland forest. A 165-ha area in the southeast portion of the study area was damaged by fire associated with the El Niño-Southern Oscillation (ENSO) event of 1997. The home ranges of 36 groups of siamangs are found within or partially within the research area. Siamang group density in the unburned portion of the study area is approximately 4.11 groups $/ \mathrm{km}^{2}$ [O'Brien et al., 2003].

\section{Genetic Data Collection}

Fecal samples were collected opportunistically between May 2001 and March 2002 from members of seven habituated siamang groups that were being observed as a part of other studies [Lappan, 2005; O'Brien et al., 2003] (A. Roshyd, unpublished data).

I placed approximately $2 \mathrm{ml}$ of fresh fecal material in an $8 \mathrm{ml}$ sterile vial with approximately $4 \mathrm{ml}$ of RNA-later ${ }^{\circledR}$ (Ambion Inc., Austin, TX). Samples were then stored at ambient temperature in the field for 1-21 days, and were then frozen in 
694 / Lappan

TABLE I. Primers Used for Amplification and Sequencing of a 350-bp Fragment of the HV1 Region of Siamang Mitochondrial DNA

\begin{tabular}{lll}
\hline Type & Direction & \multicolumn{1}{c}{ Primer sequence $\left(5^{\prime}-3^{\prime}\right)$} \\
\hline Amplification & Forward 1 & CCAATACACCGGTCTTGTAAGCCGGA \\
& Reverse 1 & TGGAGAGCTCCCGTGACTGGTTAATAGG \\
& Forward 2 & AGCTGTTTTGAGTACAACCCTAGTACAACC \\
Sequencing & Reverse 2 & CGGGATGTTGATTTCACGGAGGATGCTGG \\
& Forward 1 & ACATTACTGCTAGTCC \\
& Forward 2 & AAGCAAGCACTAGAATCC \\
& Reverse 1 & TGGAAAGCTCCCGTGACTGGTTAATAGG \\
& Reverse 2 & TGTGAGTTGATTGTGGATTGG \\
& Reverse 3 & CCGAGAGGTAAGAACC \\
\hline
\end{tabular}

a standard household freezer $\left(<0^{\circ} \mathrm{C}\right)$ in Indonesia for a period of 6-18 mo. Samples were thawed for shipping from Indonesia to the United States (total time at ambient temperature of approximately 7 days), then frozen at $-80^{\circ} \mathrm{C}$ prior to DNA extraction and sequencing, which was conducted between September 2002 and March 2003 (0 to 6 mo following transport to the United States).

Extraction and sequencing was conducted at the New York University Molecular Anthropology Laboratory. I extracted whole genomic DNA from the fecal samples using the QIA-amp Stool Mini-kit ${ }^{\circledR}$ (Qiagen Inc., Valencia, CA) and manufacturer-supplied protocols. Then, using the polymerase chain reaction (PCR), I amplified a 350-base-pair fragment of the Hypervariable-1 (HV1) region of the mitochondrial genome from each individual using two sets of primers designed by Kirsten Sterner from published gibbon d-loop sequences [Roos \& Geissmann, 2001]. I then purified and sequenced the amplified fragments using either an ABI Prism ${ }^{\circledR} 373$ Automated Sequencer (Applied Biosystems Inc., Foster City, CA) with Dye-Terminator ${ }^{\circledR}$ chemistry (Applied Biosystems Inc.) and manufacturer-supplied protocols, or an ABI 310 Automated Sequencer with ABI Big Dye ${ }^{\mathbb{R}}$ chemistry (Applied Biosystems Inc.) and manufacturer-supplied protocols. I fully sequenced the relevant region in both directions, and aligned and compared the resulting sequences using Sequencher software (Gene Codes Corp., Ann Arbor, MI) and the default settings. Alignments were then optimized manually. Primers are described in Table I.

To exclude the possibility of human contamination, positive controls were conducted employing the author's DNA as a template. Human mitochondrial DNA failed to amplify using the gibbon-specific HV1 primers and the optimized protocols.

Amplification of nuclear DNA from the extracted siamang DNA was possible, but proved difficult, with fewer than one in three attempts resulting in a usable product, whereas mitochondrial DNA amplified readily. For this reason, the sequences produced using the gibbon HV1-specific primers were assumed to reflect actual mitochondrial sequences, rather than nuclear inserts. To confirm this assumption, DNA from three known mother-offspring pairs was sequenced to confirm sequence matching between matrilineal relatives. In each case, the sequences were a perfect match.

\section{RESULTS}

\section{Distribution of Haplotypes in a Neighborhood}

A total of nine haplotypes differing by one to 21 base-pairs were identified in 15 adults in six neighboring groups south of the Canguk River (Fig. 1), and two 




Fig. 1. Approximate territories and HV1 haplotypes of siamang adults south of the Canguk River. Circles indicate adult females, triangles indicate adult males. Each known haplotype is indicated by a unique number (1-9). "Burned Area" indicates habitat damaged in the El Niño-Southern Oscillation wildfires of 1997.

additional haplotypes were identified in a three-adult group north of the Canguk River. The sequences have been submitted to GenBank and given the accession numbers DQ862100-DQ862117.

As the mutation rate in the hominoid HV1 region is approximately $7 \times 10^{-3}$ point mutations per generation in a fragment of this length (calculated using rates published by Howell et al. [2003]), individuals have a very high probability of having identical HV1 haplotypes with their mothers and maternal siblings. The probability of having identical haplotypes remains above $95 \%$ for individuals separated by fewer than seven transmission events. Therefore, individuals with different haplotypes are unlikely to be close matrilineal relatives.

In contiguous groups $\mathrm{B}, \mathrm{C}, \mathrm{F}, \mathrm{G}$, and $\mathrm{S}$, a higher percentage of adult males $(50 \%, \mathrm{n}=8)$ than adult females $(16.7 \%, \mathrm{n}=6)$ shared a haplotype with at least one member of an immediately adjacent group. This trend persisted if only samesex individuals were considered (37.5\% of males vs. $0 \%$ of females). The presence of multimale groups (and absence of multifemale groups) in the neighborhood is not sufficient to explain this pattern, as the clustering of male haplotypes involves members of different groups. 


\section{6 / Lappan}

\section{Distribution of Haplotypes Within Groups}

While gibbons are generally described as socially monogamous, there have been reports of gibbon groups containing three or more adults (reviewed by Fuentes [2000] and Reichard [2003]). In most cases, information about the stability of these groups is unavailable. However, multimale groups of Hylobates lar at Khao Yai were stable in composition for over a year [Brockelman et al., 1998; Sommer \& Reichard, 2000]. In this study, four of the seven groups contained two adult males (adulthood being defined by a fully adult appearance, including fully erupted canines, and the observation of adult social behaviors, such as participation in territorial defense, coordination of activities with the adult female, and participation in vocal duets), and multimale grouping persisted for periods of several years. In three of the four multimale groups, all three adults had different haplotypes (Fig. 1; haplotypes in group A: adult female $=11$, adult male $1=10$, adult male $2=2$ ), which suggests that in these groups, neither adult male was the offspring of the adult female, and that adult group members were not maternal siblings. These data suggest that established pairs may under some circumstances accept adult male immigrants, or that adult male "stepsons" of the adult female may be retained in the group. In group F, one adult male shared a haplotype with the adult female. With the exception of female $\mathrm{F}$, each adult female in the study had a haplotype differing from that of each male in her group.

\section{DISCUSSION}

While previous siamang studies report observations of both males and females transferring to neighboring groups [Chivers \& Raemaekers, 1980; Palombit, 1992, 1994], observations of solo calling by maturing or unmated adult males on the periphery of the home range [Chivers \& Raemaekers, 1980; Palombit, 1992] and "floating" females [Chivers \& Raemaekers, 1980] suggest that females may spend more time not associated with social groups, and may disperse greater distances than males. In this study, the presence of multiple haplotypes among adult females, coupled with the absence of clustering of female haplotypes, suggests that maturing female offspring in the study neighborhood did not typically emigrate to neighboring groups. The presence of some clustering of adult male haplotypes suggests that short dispersal distances among males in this population may be relatively common, but the presence of several unique male haplotypes in the study area, and observations of male disappearances from the study neighborhood [Lappan, 2005] suggest that male dispersal distances in the study area may be variable.

Female transfer to a group adjacent to the natal group may be rare for one of two reasons. Females may generally transfer to more distant areas, or female mortality prior to or during transfer may be very high, making successful female transfer rare on any spatial scale. Two subadult females in the study population were aggressively evicted from their purportedly natal groups by adult females, and subsequently disappeared from the study neighborhood [Lappan, 2005]. If aggressive eviction of female offspring is common at Way Canguk, then maturing females may be forced to seek breeding opportunities in areas distant from the natal group, rather than waiting for breeding positions to become available in nearby groups. Several researchers [Leighton, 1987; Mitani, 1990; Palombit, 2000] have argued that dispersal-related mortality for gibbons is high, but to date a sex difference in dispersal-related mortality in gibbons has not been documented. At Way Canguk, the available siamang habitat is saturated [O'Brien et al., 2003], rates of mortality among breeding adults are low (T. O'Brien and M. Kinnaird, unpublished data), and nonterritorial adult-sized animals (floaters) 
are rare, which suggests that competition for breeding opportunities is intense. The fact that second adult males (but not second adult females) were found in a number of siamang groups suggests that relative to females, maturing males at Way Canguk may have a broader set of behavioral options (including delayed dispersal and formation of polyandrous groups), which may lead to sex differences in dispersal-related mortality. Further demographic research and genetic studies including samples from a broader geographic range would be required to better understand the effects of sex-specific mortality and dispersal patterns on the distributions of siamang haplotypes in a neighborhood.

The study neighborhood was small, and sampling was incomplete (e.g., groups $\mathrm{L}$ and $\mathrm{U}$ were not sampled). Therefore, it is likely that some study adults had additional nearby matrilineal relatives that remained undetected. Given the limited sample size, the high haplotype diversity detected in the study neighborhood is surprising, and may reflect greater-than-anticipated mean female dispersal distances, or very high female dispersal-related mortality. However, it is also possible that the haplotype diversity in the study neighborhood is related to its proximity to an area severely damaged during the El Niño-Southern Oscillation wildfires of 1997 (Fig. 1). No siamang groups at Way Canguk had home ranges consisting entirely of fire-damaged habitat, which suggests that the fires substantially reduced the area of appropriate siamang habitat, which may have caused crowding in neighboring areas. Additional population genetic research in disturbed and undisturbed areas would be helpful in determining the effects of fire on patterns of dispersal and group formation in siamangs.

\section{ACKNOWLEDGMENTS}

Permission to conduct research in Indonesia was granted by the Indonesian Institute of Sciences (LIPI), and permission to conduct research in the Bukit Barisan Selatan National Park was granted by the Indonesian Ministry of Forestry's Department for the Protection and Conservation of Nature (PHKA). Permission to export fecal samples from Indonesia was granted by the Indonesian Ministry of Forestry. Special thanks to Pak Munifol at the Balai Taman Nasional Bukit Barisan Selatan, and to Pak Jati at the Department of Forestry for all of their assistance and kindness. Thanks to the American Indonesian Exchange Foundation (AMINEF), Universitas Indonesia and the Wildlife Conservation Society-Indonesia Program for considerable logistical assistance in Indonesia, and to Anton Nurcayho, Maya Dewi Prasetyaningrum, Mohammad Iqbal, Teguh Priyanto, Tedy Presetya Utama, Janjiyanto, Sutarmin, Martin Trisunu Wibowo, and Abdul Roshyd for their assistance in the field. Thanks to Todd Disotell, Tony Di Fiore, Andy Burrell, Stephen Clifford, Ryan Raaum, Kirsten Sterner, Tony Tosi, and Danielle Whittaker for their assistance and advice in the laboratory, and to Marina Cords, Roberto Delgado, Tony Di Fiore, Terry Harrison, Clifford Jolly, Tim O'Brien, Ryne Palombit, and an anonymous reviewer for helpful comments on previous versions of this manuscript.

\section{REFERENCES}

Brockelman WY, Reichard U, Treesucon U, Raemaekers JJ. 1998. Dispersal, pair formation and social structure in gibbons (Hylobates lar). Behav Ecol Sociobiol 42: 329-339.
Chivers DJ, Raemaekers JJ. 1980. Long-term changes in behaviour. In: Chivers DJ, editor. Malayan forest primates: ten years' study in tropical rain forest. New York: Plenum Press. p 209-258. 


\section{8 / Lappan}

Faulkes CG, Arruda MF, Monteiro da Cruz MAO. 2003. Matrilineal genetic structure within and among populations of the cooperatively breeding common marmoset, Callithrix jacchus. Mol Ecol 12:1101-1108.

Fuentes A. 2000. Hylobatid communities: changing views on pair bonding and social organization in hominoids. Yearb Phys Anthropol 43:33-60.

Gerloff G, Hartung B, Fruth B, Hohmann G, Tautz D. 1999. Intracommunity relationships, dispersal pattern and paternity success in a wild living community of bonobos (Pan paniscus) determined from DNA analysis of faecal samples. Proc R Soc Lond B Biol Sci 266:1189-1195.

Howell N, Smejkal CB, Mackey DA, Chinnery PF, Turnbull DM, Herrnstadt C. 2003. The pedigree rate of sequence divergence in the human mitochondrial genome: there is a difference between phylogenetic and pedigree rates. Am J Hum Genet 72:659-670.

Kappeler PM, Wimmer B, Zinner D, Tautz D. 2002. The hidden matrilineal structure of a solitary lemur: implications for primate social evolution. Proc R Soc Lond B Biol Sci 269:1755-1763.

Koenig WD, Van Vuren D, Hooge PN. 1996. Detectability, philopatry, and the distribution of dispersal distances in vertebrates. Trends Ecol Evol 11:514-517.

Lappan S. 2005. Biparental care and male reproductive strategies in siamangs (Symphalangus syndactylus) in southern Sumatra. Ph.D. dissertation[UMI number 3157833]. New York: New York University.

Leighton DR. 1987. Gibbons: territoriality and monogamy. In: Smuts BB, Cheney DL, Seyfarth RM, Wrangham RW, Struhsaker TT, editors. Primate societies. Chicago: University of Chicago Press. p 135-145.

Mitani JC. 1990. Demography of agile gibbons (Hylobates agilis). Int J Primatol 11:411-424.

O'Brien TG, Kinnaird MF, Nurcahyo A, Prasetyaningrum M, Iqbal M. 2003. Fire, demography and the persistence of siamang (Symphalangus syndactylus: Hylobatidae) in a Sumatran rainforest. Anim Conservation 6:115-121.

Palombit RA. 1992. Pair bonds and monogamy in wild siamang (Hylobates syndactylus) and white-handed gibbon (Hylobates lar) in Northern Sumatra. Ph.D. dissertation. Davis, CA: University of California, Davis. 453p.

Palombit RA. 1994. Dynamic pair bonds in hylobatids: implications regarding monogamous social systems. Behaviour 128:65-101.

Palombit RA. 2000. Infanticide and the evolution of male-female bonds in animals. In: van Schaik $\mathrm{CP}$, Janson $\mathrm{CH}$, editors. Infanticide by males and its implications. Cambridge: Cambridge University Press. p 239-268.

Raemaekers JJ, Raemaekers PM, Haimoff EH. 1984. Loud calls of the gibbon (Hylobates lar): repertoire, organization and context. Behaviour 91:146-189.

Reichard UH. 2003. Social monogamy in gibbons: the male perspective. In: Reichard UH, Boesch C, editors. Monogamy: mating strategies and partnerships in birds, humans and other mammals. Cambridge: Cambridge University Press. p 190-213.

Roos C, Geissmann T. 2001. Molecular phylogeny of the major hylobatid divisions. Mol Phylogenet Evol 19:486-494.

Sommer V, Reichard U. 2000. Rethinking monogamy: the gibbon case. In: Kappeler PM, editor. Primate males: causes and consequences of variation in group composition. Cambridge: Cambridge University Press. p 159-168.

Srikosamatara S. 1984. Ecology of pileated gibbons in south-east Thailand. In: Preuschoft H, Chivers DJ, Brockelman W, Creel $\mathrm{N}$, editors. The lesser apes: evolutionary and behavioural ecology. Edinburgh: Edinburgh University Press. p 242-257.

Wimmer B, Tautz D, Kappeler PM. 2002. The genetic population structure of the gray mouse lemur (Microcebus murinus), a basal primate from Madagascar. Behav Ecol Sociobiol 52:166-175. 